\title{
FILOSOFÍA CIUDADANA
}

\author{
CiVtc Philosophy \\ Enrico Brugnami \\ DOI: 10.26754 /ojs_arif/arif.202125436
}

Miguel Ángel Quintanilla (2020): Filosofía ciudadana. Ed. Trotta, Madrid. 193 pp.

Suele concebirse la filosofía como una actividad eminentemente académica. De hecho, así es. Es el colectivo docente e investigador quien, en mayor medida, tiene la filosofía como profesión. Son sus integrantes quienes se dedican a pensarla, crearla y enseñarla. Sin embargo, podríamos preguntarnos ¿pertenece en exclusiva a ellos?, o, dicho de otra manera, ¿sólo en la academia nos encontramos con la filosofía? La respuesta: no. Todas las personas, en la medida en que son ciudadanas del mundo, son susceptibles de vérselas con los problemas que la filosofía plantea. Esta es una de las tesis que se defienden en la obra que aquí reseñamos, Filosofía ciudadana (2020), donde leemos: «En realidad, nos topamos con ellas [las ideas filosóficas] a cada paso que damos en nuestra vida diaria: cuando nos esforzamos por entender el mundo que nos rodea, su sentido, su valor y su interés para nosotros» (p. 18). Ya el título de la obra es significativo, pues nos sugiere que la reflexión filosófica que encontramos en sus páginas está muy apegada a los problemas de la ciudadanía y a los desarrollos sociales, políticos y tecnocientíficos.

Su autor es Miguel Ángel Quintanilla Fisac. Nacido en Segovia en el año 1945, es actualmente catedrático emérito de Lógica y Filosofía de la Ciencia de la Universidad de Salamanca. Sigue siendo actualmente uno de los filósofos españoles más importantes y prolíficos desde el inicio de la democracia en España. Es autor de un gran número de libros y artículos sobre filosofía, tecnología, ciencia y política, de entre los cuales cabe destacar Fundamentos de lógica y teoría de la ciencia (1981), A favor de la razón (1981), Tecnología, un enfoque filosófico (1988), La utopía racional (1989), escrito junto a Ramón Vargas-Machuca, y Tecnologías entrañables (2017), escrito junto a Martín Parselis, Diego Lawler y Darío Sandrone.

Además de su labor filosófica, cabe destacar su compromiso con la política científica y universitaria. Ha sido Senador por Salamanca (1982-1989), Secretario 
General del Consejo de Universidades (1991-1995) y Secretario de Estado de Universidades e Investigación (2006-2008). Fundó el Instituto Universitario de Estudios de la Ciencia y la Tecnología (ECYT) y lo dirigió hasta el año 2015. Actualmente preside la Fundación Centro de Estudios para la Ciencia, la Cultura Científica y la Innovación (3CIN).

Filosofía ciudadana es una obra escrita en Salamanca, entre los años 2008 y 2019. Está dividida en cuatro partes. La primera está dedicada a la filosofía, la segunda a la innovación, la tercera a la cultura científica y la cuarta a la política. La obra no se nos presenta como un ensayo unitario, ni un tratado, ni un manual. Cada parte está comprendida de breves textos autoconclusivos (de entre una y tres páginas aproximadamente), cada uno de los cuales está encabezado por la tesis que en él se defiende. Todos los textos aparecieron previamente, ya sea en la edición impresa del diario Público como en emisiones radiofónicas semanales de la cadena Onda Cero de Salamanca, además de en el blog del autor https://maquinta.wordpress.com/. Dada esta composición fragmentaria del libro y de su marcado carácter filosófico no podemos sino acordarnos de obras como La felicidad de los pececillos (2011) de Simon Leys y de la ya famosa La utilidad de lo inútil (2013) de Nuccio Ordine.

El objetivo de la obra es claro desde el principio. Miguel Ángel Quintanilla busca recuperar el programa de la Ilustración: «pensar para saber, saber para poder, poder para hacer lo que queremos» (p. 13). No es un regreso sin más a las tesis de la Ilustración, sino que busca reelaborarlas a partir de unas bases más modestas, realistas y materialistas, pero también más decisivas. Se trata de construir una humanidad responsable con el planeta y consigo misma. Este querer recuperar el proyecto ilustrado tiene un doble motivo. Por una parte, las condiciones científicas y tecnológicas nunca han posibilitado tanto en la historia de la humanidad que podamos «entender el mundo y transformarlo de acuerdo con nuestros deseos» (Ibid.). Por otra parte, cada vez tenemos menos tiempo para pensar el mundo que habitamos y poder analizar y pensar con profundidad nuestra circunstancia. Por ello, porque tenemos la capacidad de hacerlo, pero no la disposición temporal, debemos recuperar el hábito del pensar despacio y con mesura, sin afán de inmediatez. Filosofía ciudadana sirve a este propósito de la siguiente manera: presenta al lector breves ensayos sobre temas muy concretos para que, a partir de ellos, piense y reflexione por su propia cuenta. Así, no busca Quintanilla tener la última palabra ni sentenciar ninguna verdad. Más bien trata de estimular la capacidad crítica de la ciudadanía.

Pese a que Kant no aparece mencionado ni referenciado, la obra entronca claramente con la concepción kantiana de la Ilustración. En ella, el sapere aude o 
el atreverse a pensar por uno mismo está en relación no sólo con la disposición personal de ejercer un pensamiento libre y autónomo, sino también con la difusión social del mismo pensamiento. Kant se refiere a esta difusión como el uso público de la razón. Quintanilla hace buena muestra de este uso, pues Filosofía ciudadana es un libro publicado y cuyos textos fueron a su vez publicados y retransmitidos de manera pública en un pasado. Que, además, apareciesen muchos de ellos en el diario Público no hace sino confirmar de manera anecdótica este hecho.

Su objetivo de estimular el pensamiento crítico y autónomo de sus lectores para que sigan investigando por sí mismos muestra un interesante paralelismo con el final de la Crítica de la razón pura, donde Kant nos recuerda que «solo queda el camino crítico» (A 856 / B 884). En este camino crítico no se trata de llevar razón y poseer la verdad, pues el ser humano es epistémicamente falible, sino de estar en la razón y de ejercitarla (como nos recuerda el propio autor en su A favor de la razón). Incluso las diversas ciencias pueden y deben poder equivocarse, más no por ello deben quedar fuera de la razón. El racionalismo de Quintanilla es, como el de Karl Popper, un racionalismo crítico y con miras al progreso.

En la primera parte del libro se define a la filosofía como una forma de pensar abstractiva, rigurosa y generalista, con afán crítico, más que como un conjunto de conocimientos privilegiados (pp. 18 y 37). En toda esta primera parte se defiende una concepción de la filosofía muy ligada a las ciencias (sobre todo a las ciencias naturales). Solo mediante el conocimiento científico podemos comprender el mundo que nos rodea cada vez más satisfactoriamente y desarrollar estrategias que nos permitan cuidar del planeta y de nosotros mismos. Aquí, conocimiento y acción (en especial la acción del cuidado) van siempre de la mano. Del gnóthi seautón cabe pasar al cura sui, como ya hizo notar Michel Foucault en su texto La ética del cuidado de sí como práctica de la libertad (1984).

Otra de las tareas que una filosofía ligada a las ciencias debe afrontar es la de acortar el espacio del pensamiento mitológico, de las pseudociencias y de la cada vez más creciente posverdad. Según Quintanilla debemos mantener la separación entre verdad y mentira que la posverdad desdibuja y defender la noción de verdad como correspondencia con los hechos, pues es la que más se aproxima nuestro sentido común (p. 25)

La segunda parte del libro está dedicada a la innovación y al desarrollo cultural y tecnocientífico, esto es, a la actividad transformadora del ser humano mediante la cual introduce novedades en su entorno (p. 62). El concepto de innovación es fundamental en Filosofía ciudadana, pues el proyecto ilustrado de ejercer una razón autónoma se ve complementado con la búsqueda y construcción de un mundo 
mejor. Por ello la innovación no es una opción, sino más bien un imperativo (pp. 64-65). Entre los textos que conforman esta parte del libro podemos encontrar interesantes reflexiones acerca de temas tan dispares como la manipulación genética de embriones humanos, el principio de precaución en el manejo de organismos modificados genéticamente, el abuso de las farmacéuticas en la venta de fármacos, el valor social de herramientas como la Wikipedia o la obsolescencia programada de los artefactos que usamos en nuestro día a día.

En la tercera parte del libro se nos muestra la investigación científica no solo como una de las muchas innovaciones que pueden darse en la sociedad, sino como la más importante de todas ellas. Por ello insiste Quintanilla en que «el espíritu científico se difunda por toda la sociedad y fertilice no solo la economía, sino también la cultura, la política y la moral cívica» (p. 112). Entre otros, cabe destacar los textos dedicados a las teorías del riesgo, a la difusión periodística de la ciencia y manipulación de su imagen en los medios de comunicación, a la denuncia de la desigualdad de género que hay en las distintas comunidades científicas del mundo o a las consecuencias de la incultura científica en las academias y universidades que ya señalaron en su día Charles Percy Snow y Alan Sokal.

La cuarta y última parte está dedicada a pensar la actividad política y su objetivo, que no es otro que «gestionar la sociedad de manera eficiente y acorde con la voluntad de los ciudadanos que forman parte de ella» (p. 150). En el último texto expone Quintanilla su concepto de democracia y la radicalización que la misma necesita. Critica que los problemas derivados de la regla de las mayorías pongan en peligro los pilares de la democracia: igualdad, libertad y racionalidad. Frente a ello, la solución pasa por una democracia cada vez más radical. Las cuatro condiciones para la radicalización de la democracia son: 1) una libertad de expresión política real y garantizada, 2) que la igualdad de oportunidades en la participación de las decisiones políticas sea una igualdad material y no solo formal, 3) la transparencia y publicidad real de la información verdaderamente importante para poder tomar decisiones colectivas y 4) poder desobedecer una decisión colectiva y resistir pacíficamente su imposición siempre y cuando dicha decisión colectiva vaya en contra de cualquiera de las anteriores tres condiciones (p. 185-186). Otros textos de especial importancia en esta última parte de la obra son los dedicados a la política universitaria, al nacionalismo catalán o a la situación de los miles de refugiados que hay en Europa.

En conclusión, Filosofía ciudadana nos brinda la posibilidad de acceder a un gran número de reflexiones sugestivas y tremendamente actuales sobre filosofía, ciencia, tecnología y política de la mano de Miguel Ángel Quintanilla, cuya dilatada 
experiencia en todos estos campos no hace sino dotar de más valor la obra que aquí reseñamos. Pensar críticamente, aumentar nuestro conocimiento, investigar para innovar y cuidar de nuestro planeta y nuestra sociedad son las principales lecciones que se desprenden de Filosofía ciudadana. Quintanilla nos viene a recordar que 240 años después de la publicación de la Critica de la razón pura nos sigue quedando solamente el camino crítico. Más nos vale recorrerlo con éxito para poder asegurar el progreso social y el cuidado de los valores morales y la dignidad humana.

\author{
Enrico Brugnami \\ Universidad de La Laguna \\ ebrugnam@ull.edu.es
}

